\title{
Antinociceptive and Anti-inflammatory Effects of Diclofenac Sodium Along with B Vitamins on Acute Pulpitis
}

\author{
Rumana Kabir ${ }^{1}$, Nasim Jahan ${ }^{2}$, Nayma Sultana ${ }^{3}$, Rama Choudhury ${ }^{4}$
}

\begin{abstract}
Background: In acute pulpitis intense pain and inflammatory changes are the main features of the patients. Diclofenac sodium is commonly used in the treatment of dental pain but has many side effects. To reduce the dose and duration of traditional analgesic drugs several members of $B$ vitamins $\left(\mathrm{B}_{1}, \mathrm{~B}_{6}, \mathrm{~B}_{12}\right)$ can be used. Objective: To observe the combined effects of diclofenac sodium with $\mathrm{B}$ vitamins in acute pulpitis patients. Method: This prospective interventional study was carried out in the Department of Physiology, Sir Salimullah Medical College (SSMC), Dhaka between July 2014 and June 2015. Ethical permission was taken from the Institutional Ethics Committee (IEC) of SSMC. Sixty diagnosed acute pulpitis patients of both sexes, aged 18-40 years were included by purposive sampling from the Out Patient Department of Dental unit of SSMC. They were divided into 2 groups (30 patients in each group), as diclofenac treated group received only diclofenac sodium (DS) for 5 days and combined treated group received combination of DS with B vitamins (BV) for same duration (DS\&BV). Both the groups were studied two times i.e before taking Diclofenac Sodium on day 1 (DS d 1), after taking Diclofenac Sodium on day 5 (DS d 5) and before taking both DS with B vitamins on day 1 (DS \& BV d 1), after taking both DS with B Vitamins on day 5 (DS \& BV d 5). The intensity of pain was scored by Visual Analog Scale (VAS) by using a Verbal Descriptive Scale (VDS) as a guide. Again, serum CRP level was measured by latex method. The statistical analysis was done by paired sample ' $t$ ' test. Results: In this study, VAS score ( $<<0.001, p<0.01$ respectively) and serum CRP $(\mathrm{p}<0.001)$ level were significantly reduced in acute pulpitis patients after 5 days treatment of diclofenac sodium with B vitamins supplementation in comparison to their pre supplemented state and to the patients treated with only diclofenac sodium. Conclusion: The present study revealed that, the combination of diclofenac sodium along with B vitamins reduce pain and inflammation more efficiently than the treatment with diclofenac alone.
\end{abstract}

Key words: Acute pulpitis, diclofenac sodium, B vitamins, VAS.

J Bangladesh Soc Physiol. 2016, June; 11(1): 29-34 For Authors Affiliation, see end of text.

http://www.banglajol.info/index.php/JBSP

\section{Introduction}

A cute pulpitis is an inflammatory condition of dental pulp caused by noxious stimuli in which the pulp is capable of returning to the normal state following removal of the stimuli ${ }^{1}$. It is characterized by pain and inflammation ${ }^{2}$. Pain is a protective

Received 15th Nov. 2015; Accepted 24th April. 2016 mechanism of the body. It occurs whenever tissues are being damaged and it causes the individual to react to remove the pain stimulus. Pain is classified clinically into two types, acute and chronic. Acute pain or fast pain is the pain which is felt within 0.1 second after application of pain stimuli which is conducted by type $\mathrm{A}^{\prime}$ fiber. Whereas, chronic pain begins after 1 second or more and conducted by type $\mathrm{C}$ fiber ${ }^{3}$.

J Bangladesh Soc Physiol. 2016, June; 11(1): 29-34 
Management of pain involves the administration of both opioid and non-opioid analgesics. Non opioids include acetaminophen and non-steroidal anti-inflammatory drugs (NSAID). However, nonsteroidal anti-inflammatory drugs (NSAID) are commonly used for the control of moderate to severe intensity of pain. The commonly used NSAID are ibuprofen, etoricoxib, diclofenac etc ${ }^{4}$. Among them diclofenac sodium exhibits potent analgesic and anti-inflammatory effects ${ }^{5}$, and is commonly used in the treatment of dental pain ${ }^{6}$.Although the traditional analgesics can alleviate pain and anxiety effectively and facilitates wound healing but they produce some side effects like gastritis, nausea, vomiting, bleeding, sedation and hypersensitivity reactions etc ${ }^{4}$.

Again, vitamin B is a water soluble vitamin which includes thiamine, riboflavin, niacin, pantothenic acid, pyridoxine, biotin, folic acid, cobalamins ${ }^{7}$. However, B vitamins in their separate forms have analgesic effects such as thiamin (vitamin $\mathrm{B}_{1}$ ) has analgesic and anti-inflammatory effects in mice ${ }^{8}$, pyridoxine (vitamin $\mathrm{B}_{6}$ ) has analgesic effects in diabetic peripheral neuropathic patients ${ }^{9}$, cyanocobalamin (vitamin $\mathrm{B}_{12}$ ) has analgesic effects in low back pain ${ }^{10}$. Moreover, vitamin $\mathrm{B}_{12}$ can relieved pain after short and prolonged period of supplementation on rats ${ }^{11}$.

Again, combined supplementation of B vitamins (thiamin, pyridoxine and cyanocobalamin) with diclofenac sodium have more analgesic and antiinflammatory effects. Such as B vitamins has been used, in combination with diclofenac for various painful diseases such as, in the treatment of vertebrogenic lumbosacral rediculopathy ${ }^{12}$, in lumbago ${ }^{13}$, pain originated from tonsillectomy ${ }^{14}$, in acute pain originated by lower limb fracture and surgery ${ }^{5}$. In addition, vitamin $B$ can potentiate the analgesic effect of diclofenac sodium in carrageenin induced hyperalgesia in rat $^{15}$.

Pain intensity is measured by Visual Analog Scale (VAS) scoring using Verbal descriptive scale as guide $^{16,17,18}$ and inflammatory status is observed by measuring serum $C$ reactive protein (CRP) level.C-reactive protein (CRP) is an acute-phase protein. It is mostly synthesized in the liver and the concentration in plasma may be increased several hundred fold in response to inflammatory stimuli $^{19}$. C reactive protein (CRP) level was reduced after supplementation of folic acid and other vitamin B complex in stable hemodialysis patients ${ }^{20}$. This CRP level was also reduced in some obese diabetic patients having chronic inflammation after 3 months supplementation of diclofenac sodium ${ }^{21}$.

The combination of diclofenac with $\mathrm{B}$ vitamins have a different and complementary analgesic mechanism of action and could show a better analgesic effect than single drug alone ${ }^{14}$. Diclofenac has the risk of gastrointestinal side effects by damaging the gastric mucosa ${ }^{19}$. To lower the risk of such adverse effects, the duration of diclofenac treatment can be limited by combined treatment of diclofenac with $\mathrm{B}$ $\operatorname{vitamins}^{13}$.

Though, Some studies have been done in home ${ }^{11}$ as well as in abroad ${ }^{12,13}$ regarding the effects of diclofenac sodium along with $\mathrm{B}$ vitamins on reducing pain and inflammation in some painful diseases, but little is known regarding this combined treatment on acute pulpitis patients in our country as well in abroad. So, this study was undertaken. It is expected that the findings of this study will be beneficial for the faculty of dentistry for better management of acute pulpitis patients and can reduce the adverse effects of traditional analgesics.

\section{Methods}

This prospective interventional study was carried out in the Department of Physiology, SSMC, Dhaka between July 2014 and June 2015. The study protocol was approved by the Institutional Ethics Committee (IEC) of SSMC. Sixty diagnosed acute pulpitis patients of both sexes, aged 18-40 years were included by purposive sampling from the Out Patient Department of Dental unit of SSMC, Dhaka. They were divided into 2 groups (30 patients in each group), as 
diclofenac treated group received only diclofenac sodium (DS) at a dose of $50 \mathrm{mg} 12$ hourly for 5 consecutive days and combined treated group received combination of DS (50 mg 12 hourly for 5 consecutive days) with B vitamins (BV) at a dose of $B_{1}: 100 \mathrm{mg}, B_{6}: 200 \mathrm{mg}$ and $B_{12} 200 \mu \mathrm{g}$ 12 hourly for same duration (DS \& BV). Both the groups were studied two times i.e before taking Diclofenac Sodium on day 1 (DS d 1), and the same subjects after taking Diclofenac Sodium on day 5 (DS d 5) whereas, the other group before taking both DS with B vitamins on day 1 (DS \& BV d 1), and the same subjects after taking both DS with B Vitamins on day 5 (DS \& BV d 5). Subjects having diabetes mellitus, hypertension, heart disease, kidney disease, hypersensitivity to diclofenac sodium or $B$ vitamins, pregnancy were excluded from the study. Informed written consent was taken from each subject.

The intensity of pain was scored by Visual Analog Scale (VAS) (Figure 1) using Verbal descriptive scale (VDS) as guide ${ }^{16,17,18}$. With all aseptic precautions, five (5) $\mathrm{ml}$ of venous blood was drawn from median cubital vein by sterile disposable syringe. To assess their inflammatory changes, serum $\mathrm{C}$ reactive protein level was estimated by latex method in the Department of Microbiology BSMMU, Dhaka. Data were analyzed by Paired sample ' $t$ ' test as applicable for statistical analysis. p value $<0.05$ was taken as level of significance.

VAS is a subjective measure of pain. It is a numeric continuous scale with the higher score usually anchored with a severe pain descriptor so that a higher score indicates more pain.

VAS scoring is measured by using a metric ruler which is placed along the line with the 0 end of the ruler at the 0 (no pain) end of the scale. The point along the ruler that corresponds to the line the subject has marked on the VAS indicates the score for that subject. The markings on the VAS were measured according to the degree of pain and categorized as

- No pain 0

- Mild pain 0.1- $3 \mathrm{~cm}$

- Moderate pain 3.1- $6.9 \mathrm{~cm}$

- Severe pain 7- $10 \mathrm{~cm}$

Verbal Descriptive Scale (VDS)

When using a VDS, patients are asked to rate the intensity of their pain using a scale of descriptive words. Scale descriptions range from no pain to severe pain. The ranges of VDS are as follows-

- No pain

- Tooth felt normal, patient did not have any pain.

- Mild pain

- Recognizable, but not discomforting pain, which required no analgesics and not impair in masticatory function.

- Moderate pain

- Discomforting but bearable pain and impairment of masticatory function (analgesics if used effective in relieving pain)

- Severe pain

- Difficult to bear (analgesics if used not effective in relieving pain).

\section{Results}

All the subjects were age and BMI matched and all of them were normotensive (Table I). VAS score and serum CRP level were significantly decreased in DS \& BV d 5 in comparison to those of DS \& BV d 1 and DS d 5 (Table II).

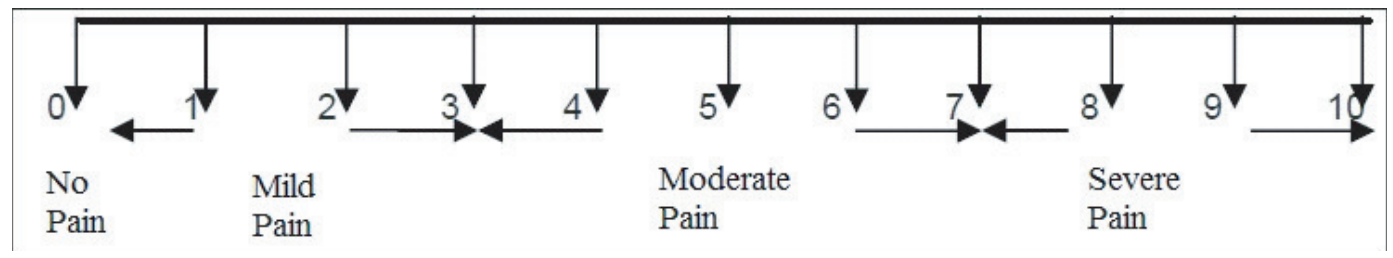

Figure 1: Visual Analog Scale (VAS) 
Table I: Age, BMI and blood pressure in both groups $(\mathrm{n}=60)$

\begin{tabular}{lcc}
\hline Parameters & DS d 1 & DS \& BV d 1 \\
\hline Age (years) & $36.60 \pm 1.86$ & $35.80 \pm 2.21$ \\
BMI $\left(\mathrm{kg} / \mathrm{m}^{2}\right)$ & $22.83 \pm 1.37$ & $23.02 \pm 1.33$ \\
SBP $(\mathrm{mm}$ of $\mathrm{Hg})$ & $111.33 \pm 3.34$ & $113.67 \pm 8.55$ \\
DBP $(\mathrm{mm}$ of $\mathrm{Hg})$ & $74.00 \pm 4.31$ & $74.67 \pm 5.5$ \\
\hline
\end{tabular}

Data are expressed as Mean \pm SD. Statistical analysis was done by independent sample t-test. DS d 1: Before taking only diclofenac sodium on day 1, DS \& BV d 1:before taking both diclofenac sodium and B vitamins on day 1, SBP: Systolic blood pressure, DBP: Diastolic blood pressure.

Table II: VAS score and serum CRP level in different groups $(\mathrm{n}=60)$

\begin{tabular}{lcccc}
\hline Parameters & $\begin{array}{c}\text { DS d 1 } \\
(\mathrm{n}=30)\end{array}$ & $\begin{array}{c}\text { DS d 5 } \\
(\mathrm{n}=30)\end{array}$ & $\begin{array}{c}\text { DS \& BV d 1 } \\
(\mathrm{n}=30)\end{array}$ & $\begin{array}{c}\text { DS \& BV d 5 } \\
(\mathrm{n}=30)\end{array}$ \\
\hline VAS score $(\mathrm{cm})$ & $6.07 \pm 0.59$ & $3.94 \pm 0.75^{* *}$ & $6.00 \pm 0.65$ & $2.27 \pm 0.45^{* * *}$ \\
Serum CRP level $(\mathrm{mg} / \mathrm{dl})$ & $15.82 \pm 3.8$ & $8.74 \pm .34^{* * *}$ & $15.68 \pm .34$ & $6.76 \pm .46^{* * *}$ \\
\hline
\end{tabular}

Data are expressed as mean \pm SD. Statistical analysis were done by Paired t-test and Independent sample t-test. DS d 1:Before taking only diclofenac sodium on day 1, DS d 5: after taking only diclofenac sodium on day 5 , DS \& BV d 1:before taking both diclofenac sodium and B vitamins on day 1, DS \& BV d 5: after taking both diclofenac sodium and B vitamins on day 5. ** = significant at $\mathrm{p}<0.05, * * *=$ significant at $\mathrm{p}<0.001$.

\section{Discussion}

In this study, VAS score was significantly reduced in acute pulpitis patients in DS \& BV d 5 in comparison to that of DS \& BV d 1 and DS d 5. This is consistent with the finding of various other investigators ${ }^{5,13}$. Again some other researchers found the dose of diclofenac $45 \%$ less in DS \& BV group ${ }^{14}$.

Again, the serum CRP level was significantly reduced in acute pulpitis patients in DS \& BV d 5 in comparison to DS \& BV d 1 and also to that of DS d 5. Similar finding was found by some other researchers ${ }^{20,21}$.

In acute pulpitis patients, pain in association with inflammation is the common complaint which occurs due to release of inflammatory mediators such as prostaglandins, TNF, IL-6, substance P, $\mathrm{C}$ reactive protein (CRP) etc ${ }^{19}$. These inflammatory mediators activate sensitive nociceptors surrounding the tooth which are responsible for inflammation and inflammatory pain ${ }^{18}$. In addition, inflammatory reactions cause intracellular accommodation of exudate in pulp and causes swelling of pulp thus creates abnormally high intra-pulpal pressure ${ }^{1}$. Moreover, richly innervated afferent nerve fibers of dental pulp causes pain transmission ${ }^{2}$. All these mechanisms involved in pain and inflammation in acute pulpitis are responsible for increasing the scoring in $\operatorname{VAS}^{18,22}$.

It has been suggested that, diclofenac sodium impairs prostaglandin synthesis ${ }^{5,13,14}$, inhibits synthesis of leukotrienes ${ }^{23}$, phospholipase $\mathrm{A}_{2}{ }^{24}$ and $\mathrm{CRP}^{21}$, thus decreases inflammation and inflammatory pain ${ }^{13,25}$ thereby decreases the scoring of VAS ${ }^{22}$.

Pyridoxine alone or in combination with thiamin and cyanocobalamin able to increase the synthesis 
and secretion of serotonin in various regions of the brain by decarboxylation of 5-hydroxytryptophan, which is the precursor of serotonin 25 .

In addition, vitamin $\mathrm{B}_{12}$ increase the secretion of noradrenalin in the CNS which act as inhibitory neurotransmitter in the nociceptive system $^{26}$. Again, vitamin $\mathrm{B}_{12}$ reduces inflammation and inflammatory pain by decreasing formation of TNF- $\pm{ }^{27}$, IL- $^{28}$ and $\mathrm{CRP}^{21}$.Moreover, some research workers stated that, accumulation of exogenous methylcobalamin promotes nerve regeneration or remyelination. Moreover, it acts as a methyl donor in DNA metabolism and causes gene transcription which may increase protein synthesis for nerve regeneration ${ }^{29}$.

In the present study, pain reducing and antiinflammatory effects were more effective in patients taken both diclofenac sodium and B vitamins, as evidenced by their VAS score and measured CRP level.

This nociceptive and anti-inflammatory effects of combined treatment may be due to their effects on reducing the formation and release of inflammatory mediators from the site of pulpitis.

\section{Conclusion}

From the results of this study, it can be concluded that, diclofenac sodium alone or in combination with $B$ vitamins have nociceptive and antiinflammatory effects in acute pulpitis patients. But the combination of diclofenac sodium along with $\mathrm{B}$ vitamins provide more efficient pain relief than treatment with diclofenac alone.

\section{Confilict of interest: None}

\section{Author Affiliation}

1. *Rumana Kabir, Assistant Professor, Department of Physiology, MH Samorita Medical College,Dhaka. Email: kabir_rumana@yahoo.com

2. Nasim Jahan, Professor \& Head, Department of Physiology, Enam Medical College, Mitford, Dhaka. Email: prof.dr.nasimjahan@gmail.com

3. Nayma Sultana, Professor, Department of Physiology, Sir Salimullah Medical College, Mitford, Dhaka. E-mail: nayma_sultana@yahoo.com

4. Rama Choudhury, Associate Professor, Department of Physiology, Sir Salimullah Medical College, Mitford, Dhaka.E-mail: mihirck2008@gmail.com

* For correspondence

\section{References}

1. Louis G, Seymour O, Carlos D. Endodontic Practice. $11^{\text {th }}$ ed. Philadelphia: PA. 1991; 136-64.

2. Pitt F. Harty's Endodontics in clinical practice. $5^{\text {th }}$ ed. New York: Churchill livingstone Elsevie 2004; 37-47.

3. Hall JE. Text book of Medical Physiology. $12^{\text {th }}$ ed. Philadepia: Elsevier India Private limited; 2011. 587.

4. Katzung G B, Masters BS and Trevor JA. Basic \& clinical Pharmacology. $12^{\text {th }}$ ed. New Delhi. Tata Mcgraw Hill Edu Pri Limi.; 2012. 643.

5. Hector PM, Mario IO, Alexis GH, Raul MM, Marisela SR, Lourdes CA, Gerardo RG. Effect of diclofenac with $\mathrm{B}$ vitamins on the treatment of acute pain originated by lower- limb fracture and surgery. Pain research and treatment. 2012; 1-5.

6. Punnagai K, Gunasekaran k, Vijaybabu K, Josephine IG. Efficacy and safety of diclofenac sodium and Etoricoxib in controlling post extraction dental painA randomized open lable comparative study. Inter J Bas Med SCi . 2010; 1: issue: 1.

7. Park K. Park's preventive and social medicine. $23^{\text {rd }}$ ed. Banarsidas bhanot publishers; 2015. 621.

8. Moallem SA, Hosseinzadeh H, Farahi S. A study of acute and chronic anti-nociceptive and antiinflammatory effects of thiamine in mice. Iran Biomed J. 2008; 12(3): 173-8

9. Ellis RL, Thomas AH, Mark F, Walter AL, Alec 1, David $\mathrm{G}$, Seymour RL. The influence of pyridoxine in diabetic peripheral neuropathy. Diabetes care. 1981; 4(6): 606-609.

10. Letiza M, Martorana U, Cataldo P, Brancato G, Letizia G. Vitamin $B_{12}$ in low back pain: a randomized, double- blind, placebo- controlled study. Eur Rev Med Pharmacol Sci. 2000; 4 (3): 53-58.

11. Masud I. Study on effects of vitamin $B_{12}$ and folic acid on pain and inflammation in rats. [Thesis]. [Dhaka], BSMMU; 2012.

12. Levin OS, Moseikin, IA. Vitamin B complex (milgamma) in the treatment of vertebrogenic lumbosacral radiculopathy. ZH Nevrol Psikhiatr Im. 2009; 109(10): 30-35.

13. Mibielli M, Geller M, Cohen J, Goldberg SG, MT Cohen, CP Nunes, Oliveira L Fonseca A. Diclofenac plus B vitamins versus diclofenac monotherapy in lumbago: the Dolor study. Current Medical Research and opinion.2009; 25: 2589-2599. 
14. Eusebio PF, Roberto MS, Gerardo RG, Eduardo MG. Combination of diclofenac plus B vitamin in acute pain after Tonsillectomy. Proc West Pharmacol Soc. 2002; 46: 88-90.

15. Reyes-Garcia G, Medina-Santilian R, Teran-Rosales F, Caram-salas, Grandos-Soto. B vitamin increase the anti-hyperalgesic effect of diclofenac in the rat. Proc. West. Pharmacol. Soc. 2002; 45:147-149.

16. Carol SB, Kim DJ. Adult measures of pain. Arthritis \& Rheumatism. 2003; 49: 96-104.

17. Adeleka OO, Christopher IU. Endodontic flare-ups: comparison of incidence between single and multiple visit procedures in patients attending a Nigerian teaching hospital. BMC oral health. 2004; 4: 4.

18. Sameer M, Nisha K, Rajan D, Navjot M, Shinam P. Efficacy of ibuprofen and paracetamol and diclofenac sodium and paracetamol on post operative pain following root canal preparation in a randomized placebo- controlled study. Indian J oral Sci. 2012; 3; 19-23.

19. Kumar V, Abbas AK, Fausto N, Aster JC. Robbins and Cortan Pathologic Basis of Disease. $8^{\text {th }}$ ed. India: Elsevier saunders. 2012; 95-160.

20. Tzu-yuan C, Kang-Ju C, Chin-Feng T, Hsiao-Min C, Hua-Chang F, Yao-min H, ming-Jei W, Huey-MT, Chang-Chung L, Kuo-Cheng L. Effects of folic acid and vitamin $\mathrm{B}$ complx on serum C-reactive protein and albumin levels in stable hemodialysis patients. Current Medical Research and opinion. 2006; 23(8): 1879-1886.

21. Maha JA, Abdullah MJ, Hussen JU and Urran. The effect of diclofenac sodium given alone or in combination with paracetamol in treatment of patients with type-2 diabetes mellitus. The Medical journal of Basrah University. 2014; 32(1): 22-29.

22. Komali G. A study of analgesic efficacy of ibuprofen and diclofenac sodium in acute pulpitis patients. J Res Adv Dent. 2013; 3(1): 49-54.

23. Ku EC, Lee W, Kothari, HV, Scholer DW. Effect of diclofenac sodium on the arachidonic acid cascade. Am J Med. 1986; 80(4): 18-23.

24. Makela A, Kuusi T, Schroder T. Inhibition of serum phospholipase-A2 in acute pancreatitis by pharmacological agents in vitro. Scand J Clin Lab Invest. 1997; 57(5): 401-7.

25. Dakshinamurti K, Sharma SK, Bonke D. Influence of $\mathrm{B}$ vitamins on binding properties of serotonin receptors in the CNS of rats. Klinische Wochenschrift. 1990; 68: 142-145.

26. Jurna I. Analgesic and analgesia- otentiating action of B vitamins. Schmerz. 1998; 12(2): 136-41.

27. Perachhi M, Catena FB, Pomati M, Franceschi M, Scalabrino G. Human cobalamin deficiency: alterations in serum tumour necrosis factor-alpha and epidermal growth factor. Eur J Haematol. 2001; 67(2): 1223-7.

28. Yamashiki M, Nishimura A, Kosaka Y. Effects of methylcobalamin (vitamin $\mathrm{B}_{12}$ ) on in vitro cytokine production of peripheral blood mononuclear cells. $\mathrm{J}$ Clin Lab Immunol. 2001; 37(4): 173-182.

29. Pfohl-Leszkowicz A, Keith G, Dirrheimer G. Effect of cobalamin derivatives on in vitro enzymatic DNA methylation: methylcobalamin can act as a methyl donor.Biochemistry.2001; 30(32): 8045-51. 